\title{
Alternative Bio-Derived JP-8 Class Fuel and JP-8 Fuel: Flame Tube Combustor Test Results Compared using a GE TAPS Injector Configuration
}

\author{
Yolanda R. Hicks, ${ }^{1}$ Sarah A. Tedder, ${ }^{2}$ Robert C. Anderson, ${ }^{3}$
}

NASA Glenn Research Center, Cleveland, Ohio, 44135, USA

This paper presents results from tests in a flame tube facility, where a bio-derived alternate fuel was compared with JP-8 for emissions and general combustion performance. A research version of General Electric Aviation (GE) TAPS injector was used for the tests. Results include combustion efficiency from gaseous emission measurements, 2D planar laser-based imaging as well as basic flow visualization of the flame. Four inlet test conditions were selected that simulate various engine power conditions relevant to NASA Fundamental Aeronautics Supersonics Project and Environmentally Responsible Aviation Program. One inlet condition was a pilot-only test point. The other three inlet conditions incorporated fuel staging via a split between the pilot and main circuits of either $10 \% / 90 \%$ or $20 \% / 80 \%$. For each engine power condition, three fuel mixes were used: $100 \% \mathrm{JP}-8 ; \mathbf{1 0 0 \%}$ alternative; and a blend of the two, containing $75 \%$ alternative. Results for the inlet cases that have fuel split between pilot and main, indicate that fuel from the pilot appears to be evaporated by the time it reaches the dome exit. Main circuit liquid evaporates within a downstream distance equal to annulus height, no matter the fuel. Some fuel fluorescence images for a $10 \% / 90 \%$ fuel staging case show a distinct difference between JP-8 and bio-derived fuel. OH PLIF results indicate that $\mathrm{OH}$ forms in a region more centrally-located for the JP-8 case downstream of the pilot, in its central recirculation region (CRZ). For the bio-derived Hydrotreated Renewable Jet (HRJ) fuel, however, we do not see much OH in the CRZ. The OH image structure near the dome exit is similar for the two fuels, but farther downstream the $\mathrm{OH}$ in the CRZ is much more apparent for the JP-8 than for the alternate fuel. For all conditions, there was no discernable difference between fuel types in combustion efficiency or emissions.

$\begin{array}{ll} & \\ \text { AST } & =\text { Advanced Subsonic Technology } \\ \text { CRZ } & =\text { central recirculation zone } \\ \text { EICO } & =\text { emission index for carbon monoxide } \\ \text { EINOX } & =\text { emission index for oxides of nitrogen } \\ \text { EP } & =\text { end point (of distillation) } \\ \text { ERA } & =\text { Environmentally Responsible Aviation } \\ \text { FAR } & =\text { fuel-to-air ratio } \\ \text { FWHM } & =\text { full width at half maximum } \\ \text { GRC } & =\text { Glenn Research Center } \\ \text { HRJ } & =\text { hydrotreated renewable jet (fuel) } \\ \text { IBP } & =\text { initial boiling point (of distillation) } \\ \text { LTO } & =\text { landing-takeoff cycle } \\ \text { NOx } & =\text { nitrogen oxides, oxides of nitrogen } \\ \text { P3 } & =\text { combustor inlet pressure } \\ \text { PLIF } & =\text { planar laser-induced fluorescence } \\ \text { PLS } & =\text { planar laser scatter } \\ \text { RMS } & =\text { Root-Mean-Square } \\ \text { SLTO } & =\text { sea level takeoff } \\ \text { T3 } & =\text { combustor inlet temperature } \\ \text { UV } & =\text { ultraviolet } \\ & \end{array}$

American Institute of Aeronautics and Astronautics 


\section{Introduction}

$\mathrm{F}$ OR more than 40 years, NASA has sustained programs to reduce the environmental effects of aviation. A major focus of these programs has been reducing the emissions of nitrogen oxides (NOx). NOx emissions decrease the protective ozone layer in the stratosphere and increase smog and ozone in the lower troposphere ${ }^{1}$. To prevent damage to the protective ozone layer, NASA programs have focused on reducing NOx emissions at cruise conditions for supersonic flight. To reduce the emissions of NOx in the lower troposphere, NASA programs have also focused on reducing NOx emissions during the landing-takeoff cycle in subsonic flight.

In addition to decreasing NOx emissions, NASA has also addressed the reduction of carbon dioxide emissions by increasing engine fuel efficiency. Increased fuel efficiency is typically achieved by increasing the engine operating pressure ratio, which increases combustor inlet temperature; however, NOx formation rates increase with higher temperatures. Without an improvement in combustor technology, higher efficiency engines will have higher, not lower, NOx emissions: improved low-NOx combustor technologies need to be developed. NASA has defined technology targets for the near term (called "N+1", circa 2015), midterm ("N+2", circa 2020) and far term ("N+3", circa 2030) that specify realistic emissions and fuel efficiency goals for commercial aircraft. In the far term, the emissions goal for supersonic cruise is less than $5 \mathrm{~g} / \mathrm{kg}$ of fuel burned, with fuel efficiency targeted at between 3.5 4.5 passenger-miles per pound of fuel ${ }^{2}$. Through the Environmentally Responsible Aviation (ERA) Program, NASA has again partnered with engine and fuel injector manufacturers to develop practical technology to meet the stringent emissions goals requirements ${ }^{3}$.

General Electric Aviation (GE) explored the Twin Annular Premixing Swirler (TAPS) injector concept ${ }^{4,5}$ in the mid-1990s, and proposed TAPS as its primary approach to achieve NASA's Advanced Subsonics Technology (AST) initiative to reduce NOx emissions below $60 \%$ of the 1996 ICAO standards, while maintaining low CO emissions. Over the years, NASA has tested selected TAPS research hardware in GRC combustor facilities, during contractual collaborations under AST, the Ultra Efficient Engine Technology (UEET), and Fundamental Aeronautics Programs. There are several configurations of the TAPS research hardware, which allow for changes in pilot and main injector hardware, domes, and cooling. GE has also investigated TAPS under the Continuous Lower Energy, Emissions and Noise (CLEEN) Program, managed by the FAA ${ }^{6}$. Figure 1 illustrates the TAPS injection concept.

NASA is also striving to develop alternatives to using refined fossil fuels derived from crude oil through collaborations such as the Alternative Aviation Fuels Experiment (AAFEX) in which international and industrial partners participate in engine tests comparing JP-grade fuels ${ }^{7,8}$. Additionally, other multinational collaborations and partners are specifying and qualifying ${ }^{9}$, characterizing ${ }^{10-14}$, and assessing the economics ${ }^{15}$ of alternative fuels. At GRC, we have tested selected alternative fuels for combustor emissions and performance using the NASA LDI concept ${ }^{16,17}$ and injectors from our industrial partners ${ }^{18,19}$.

In this paper, we look back at the archives to examine the performance during flame tube testing of one research TAPS injector. Specifically, we compare the performance at four test conditions and three fuel mixtures including $100 \%$ hydrotreated renewal jet (HRJ) fuel, 75\% HRJ and 25\% JP-8, and 100\% JP-8 fuel. The test matrix for these liquid-fuel tests at NASA included points consistent with GE N+2 cycles for Supersonics and ERA. In this work, a variety of optical techniques were used to compare the flames from the three fuel mixes. Planar laser-induced fluorescence (PLIF) of OH was used to identify where combustion-related activity occurred. Fuel PLIF was used for fuel spray patternation. Planar laser scatter (PLS) was used to locate areas where the fuel is not completely vaporized and is the direct scatter of light from fuel drops, comparable to Mie scattering. We also took images of $\mathrm{CH}$ chemiluminescence. We used high speed photography to examine global flame structure visible within the field of view.

This was the first time applying laser-based techniques to tests using an alternative fuel, so we also used this test to assess what works, particularly for fuel PLIF, because HRJ fuels have vastly fewer nascent laser-excitable fluorescent molecules. Fuel PLIF uses the fluorescence typically from laser-excited single and double ring aromatics such as methylbenzene $\left(\mathrm{C}_{7} \mathrm{H}_{8}\right)$ and naphthalene $\left(\mathrm{C}_{10} \mathrm{H}_{8}\right)$, but most alternative fuels have very little aromatic content.

American Institute of Aeronautics and Astronautics 


\section{TAPS Hardware}

The TAPS injector concept, illustrated in Fig. 1 and described in Refs. 4-6, consists of a pilot stage and a main stage, with turndown controlled by shifting the fuel distribution between the stages. As seen in this TAPS concept sketch, the pilot fuel circuit injects a conical spray from the center of the cup. When running in pilot-only mode, this zone is locally fuel-rich for added stability. The main fuel circuit feeds a number of discrete jets-in-crossflow into the surrounding annular passage as a means to promote fuel breakup, vaporization and some premixing with the incoming air before exiting the dome. Swirl is imparted to the air that flows through each circuit.

\section{Experiment Setup}

\section{A.TAPS Installation}

The combustor subcomponent facility at NASA Glenn supplies heated, non-vitiated air to the test rig. The test rig

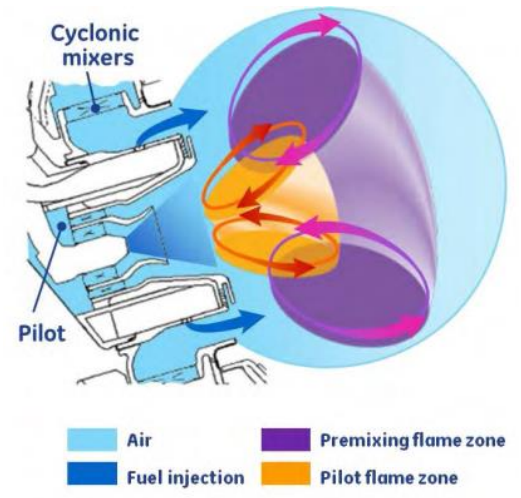

Figure 1. TAPS injection concept ${ }^{6}$

\section{B.Fuels}

JP-8 is a standard, refined aircraft engine fuel. The alternative fuel used in this study was a hydrotreated reusable jet (HRJ) fuel derived from beef tallow, and some of its physical properties are shown, along with typical characteristics for JP-8/Jet-A, in Table 1. HRJ fuel can also be derived from plant biomass, such as camolina and castor ${ }^{11,15}$. Along with plant, fat, and grease biomass fuel derivatives, alternatives have also been derived from coal and natural gas via Fischer-Tropsch processing. Most fuels compare well with refined JP-8/Jet-A class fuels in terms of physical properties such as distillation ${ }^{12}$. The alternatives have better thermal stability that Jet-A. There is not much difference in gaseous emissions, but the alternative fuels evidence a large reduction in particulate matter ${ }^{7,8,12,19}$, primarily because the alternatives have little or no aromatic content. Droplet burning rates have been compared for camolina and tallow-based HRJs and found to be similar ${ }^{13}$. For the HRJ used in the current test, the olefin content is comparable to that of JP-8, so reactivity should be similar. The higher cetane index indicates a shorter ignition delay time is likely than for the JP-8, and was determined to be the case, for example, in the comparison conducted by Allen et $\mathrm{al}^{10}$.

\section{C.Test Matrix}

A range of inlet conditions was run for extensive comparison using gas analysis. However, for comparison using optical diagnostics, a subset of four inlet conditions was used to A single TAPS cup was installed in the rig using a cylindrical cast liner, with cutouts for optical access. The TAPS injector was installed such that the optics could probe the region immediately downstream of the dump plane in the mixing region between the pilot and main circuits.
Table 1. Comparison of fuel properties

\begin{tabular}{|c|c|c|}
\hline Fuel & JP-8 & HRJ \\
\hline Sulfur (ppm) & 1148 & $<3$ \\
\hline Olefins (\%vol) & 0.9 & 0.4 \\
\hline Aromatics (\%vol) & 18.6 & 0.4 \\
\hline naphthalenes (\%vol) & 1.6 & 0 \\
\hline \multicolumn{3}{|l|}{ Distillation } \\
\hline IBP & 158 & 165 \\
\hline $10 \%$ & 176 & 179 \\
\hline $20 \%$ & 184 & 185 \\
\hline $50 \%$ & 207 & 210 \\
\hline $90 \%$ & 248 & 243 \\
\hline EP & 273 & 255 \\
\hline Residue (\%vol) & 0.8 & 1.2 \\
\hline Loss (\%vol) & 0.8 & 0.8 \\
\hline Flash Point $\left({ }^{\circ} \mathrm{C}\right)$ & 46 & 55 \\
\hline API Gravity & 41.9 & 55.1 \\
\hline Specific Gravity & 0.816 & 0.758 \\
\hline Freezing Point $\left({ }^{\circ} \mathrm{C}\right)$ & -50 & -62 \\
\hline Viscosity $\left(\mathrm{mm}^{2} / \mathrm{s}\right)$ & 4.7 & 5.3 \\
\hline Cetane Index & 41 & 67 \\
\hline Hydrogen Content (\%mass) & 13.6 & 15.3 \\
\hline Heat of combustion (MJ/kg) & 43.3 & 44.5 \\
\hline Btu/Lbm & 18616 & 19132 \\
\hline Fuel $\mathrm{H} / \mathrm{C}$ ratio & 1.88 & \\
\hline
\end{tabular}
uses a castable ceramic to form the combustor "liner". 
compare the HRJ fuel to JP-8. For each of these conditions, three fuel mixes were run, resulting in twelve test cases. In addition to the two cases of $100 \%$ JP- 8 and $100 \%$ HRJ, a mixture of the two, which is $25 \%$ JP-8/75\% HRJ was used. The mixture is not a 50-50 split because in previous alternative fuels tests, no significant cost or emissions benefit to running an even mixture was found. Point 1 is a pilot only condition and can be considered to simulate an approach condition. The remaining points have combustor pressure 200-psia and split the fuel between the pilot and main fuel circuits. Points 2 and 4 use a 10/90 pilot/main fuel split, with point 2 at lower $\mathrm{T}_{3}$; Points 3 and 4 are at the $\max \mathrm{T}_{3}$, but point 3 uses a 20/80 fuel split. Thus, we have two, 2-level comparisons, one for temperature, and the other for fuel split. Table 2 summarizes the inlet conditions used. Because we were limited in supply of the HRJ fuel, we did not take full sets of data for all twelve cases. Those conditions are described in detail later.

Table 2. Inlet conditions used for TAPS tests with optical diagnostics.

\begin{tabular}{|c|c|c|c|c|}
\hline $\begin{array}{c}\text { Test } \\
\text { Point }\end{array}$ & $\begin{array}{c}\mathrm{P}_{3} \\
\text { psia }\end{array}$ & $\begin{array}{c}\mathrm{T}_{3} \\
{ }^{\circ} \mathrm{F}\end{array}$ & $\begin{array}{c}\text { Fuel Split } \\
\text { \% Pilot/Main }\end{array}$ & FAR/FAR \\
\hline \hline 1 & 166 & 650 & $100 / 0$ & 0.48 \\
\hline 2 & 200 & 925 & $10 / 90$ & 0.94 \\
\hline 3 & 200 & 1000 & $20 / 80$ & 0.94 \\
\hline 4 & 200 & 1000 & $10 / 90$ & 0.94 \\
\hline
\end{tabular}

\section{Laser and Optical Diagnostics}

To determine the fuel spray pattern, we acquired two-dimensional images of fuel via planar laser-induced fluorescence (PLIF) and planar laser scatter (PLS). We used OH PLIF to observe the primary reactions and heat release. We acquired chemiluminescence images of $\mathrm{CH}^{*}$, which is generally concentrated near peak heat release, and visible in the reaction zone and shows where carbon-hydrogen electronic transitions occur. We also acquired high speed images of flame chemiluminescence predominantly of $\mathrm{C}_{2} *$ during combustion testing. The instrumentation setup is similar to that illustrated in Fig. 2: one camera on either side, with light collected from an angle perpendicular to the combustor flow direction.

The PLIF, PLS, and $\mathrm{CH}^{*}$ images were obtained using the same receiving optics and intensified CCD (ICCD) camera. A remotely controlled filter wheel allowed us to select a species-specific filter (FWHM

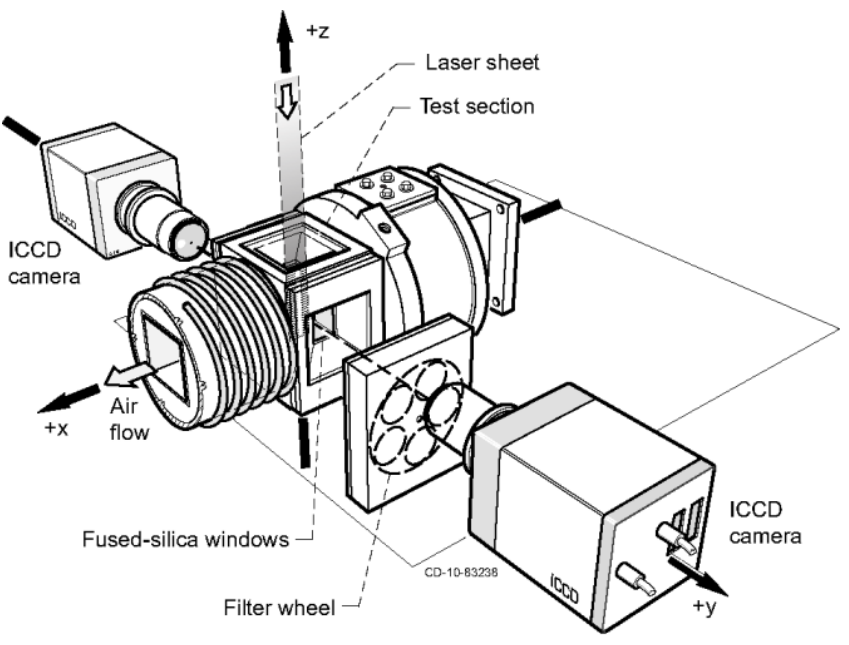

Figure 2. Schematic drawing that shows the key components used for planar laser-induced fluorescence and planer laser scattering. of 10-nm, typical) to pass light through a UV-grade, $\mathrm{f}=105-\mathrm{mm}, \mathrm{f} / 4.5$, macro camera lens. The light was then focused onto a gated, 16 -bit, $1 \mathrm{k} \times 1 \mathrm{k}$ pixel array, ICCD camera (Princeton Instruments PIMAX) having a Gen II Super-Blue-Slow-Gate intensifier. The gate time used for PLIF and PLS was 100-ns. The laser used was a 10-Hz, frequency-doubled Nd:YAG-pumped dye laser/frequency mixer system set up to produce wavelengths around $282-\mathrm{nm}$. The laser beam was formed into a sheet using a pair of cylindrical lenses, to obtain a sheet approximately $300-\mu \mathrm{m}$ thick. We typically acquired images with on-chip averages of 200 gates, and traversed across the flow along the $\mathrm{Y}$ axis in 1-mm increments. The laser sheet and collection optics were traversed together so as to maintain focus on the laser sheet. For PLIF, we collected fluorescence using a filter centered near 313-nm. For the elastically-scattered light of PLS, we used a filter centered near 280-nm. For chemiluminescence, we did not use the laser and collected light with the camera focused on a plane at $Y=0$ (coincident with the injector centerline) using a filter centered at 432-nm. We collected PLIF, PLS and $\mathrm{CH}^{*}$ data for all test matrix conditions. However, due to the limited supply of HRJ fuel, we limited full traverses for PLIF and PLS to inlet conditions 1 and 2 when using HRJ fuel.

American Institute of Aeronautics and Astronautics 
Time-resolved flame imaging was achieved using the high speed camera (Photron SA1.1), which had a 12-bit, 1024-pixel x 1024-pixel CMOS array focused on the field at $Y=0$. Light emitted from the volume within the field-ofview of the collection optics was collected. In the work presented here, we used a frame rate of 10,000 frames per second, with resultant image resolution of $768 \times 768$ pixels to capture the full field of view. The flame chemiluminescence was collected using an $f=150-\mathrm{mm}, \mathrm{f} / 1.2$ lens. High speed movies were acquired for each test case. Because we did not use a narrowband filter, the light signal is due primarily to chemiluminescence from $\mathrm{CH}^{*}$ (violet), water (red), and the $\mathrm{C}_{2} *$ Swan band which has three strong emission lines in the violet-green region with the strongest line near 515-nm. If needed to obtain reasonable exposure, we typically used neutral density filters; occasionally, we reduced the camera shutter time.

\section{Results and Discussion}

In this section, we present results from emissions gas sampling, from flame chemiluminescence, then from the laser-based techniques of PLS and PLIF. For the optical diagnostics results, images are plotted either as side views, with flow from left to right; or as end views, from an aft-looking forward perspective. In either case, the vertical axis plots the relative distance from the TAPS centerline. Keep in mind the field-of-view is the region immediately downstream of the dome. The probe volume allows us to observe the intersection of the pilot and pre-mixing flame zones.

\section{A. Gaseous emissions measurement results}

Figures $3-5$ show the emissions results from sampling the combustion gases. Combustion efficiency, emission index for oxides of nitrogen (EINOX), and emission index for carbon monoxide (EICO) are plotted as a function of fuel/air ratio by mass, calculated from the gas samples for the neat fuels, per SAE Aerospace Recommended Practice 1533 , based on the appropriate stoichiometric values of 0.0669 for HRJ and 0.0681 for JP-8. The graphs are symbol- and color-coded for inlet temperature and pressure, with solid symbols for HRJ fuel and open symbols for JP-8. These graphs show results for a different range of the inlet conditions than was used for the optical data comparison, but the range of fuel-to-air-ratio (FAR) that includes test point 4, is indicated by the blue squares.

For all conditions, there was no discernable difference between fuel types in combustion efficiency or emissions. This result is similar to other fuel comparison tests using different fuel-air mixers 16,18 .

Combustion efficiency (Fig. 3) measured for all conditions was greater than $99.9 \%$, and was greater than $99.98 \%$ for the $10 / 90$ split cases. There was some expected falloff in combustion efficiency for the pilot only condition, particularly at the lowest fuel air ratios.

For the pilot only cases, data were typically acquired at much lower FAR, in the range used for $7 \%$ and 30\% ICAO points - idle and approach — so the emissions results show that along with the slightly lowered combustion efficiency, more NOx (Fig. 4) and $\mathrm{CO}$ (Fig. 5) exit the combustor than for the $10 / 90$ split conditions.

American Institute of Aeronautics and Astronautics

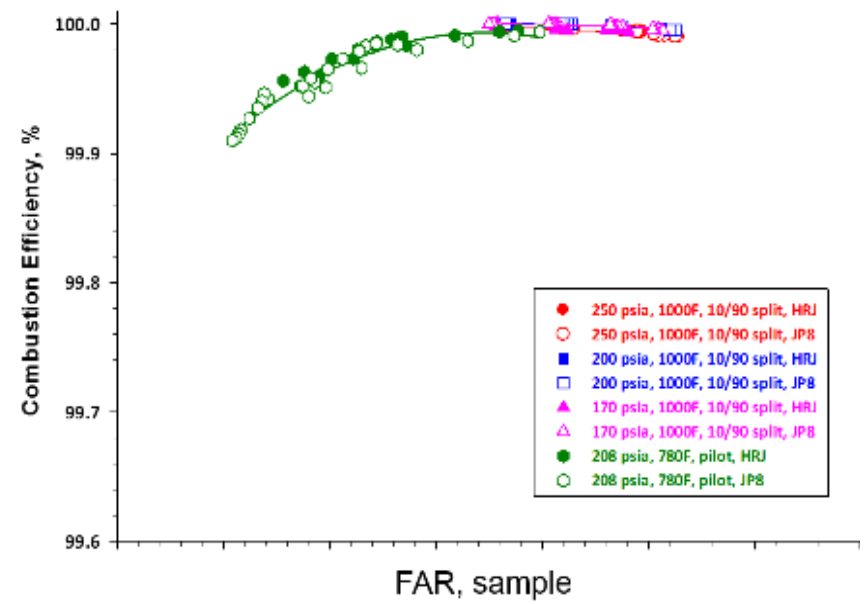

Figure 3. Combustion efficiency as a function of FAR, T3, P3, and fuel split for JP-8 and HRJ.

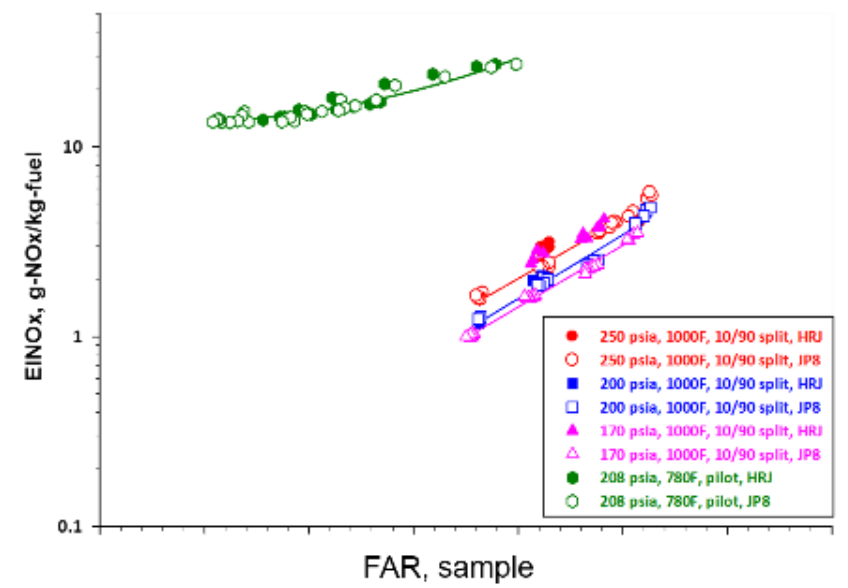

Figure 4. NOx emissions as a function of FAR, T3, P3, and fuel split for JP-8 and HRJ. 


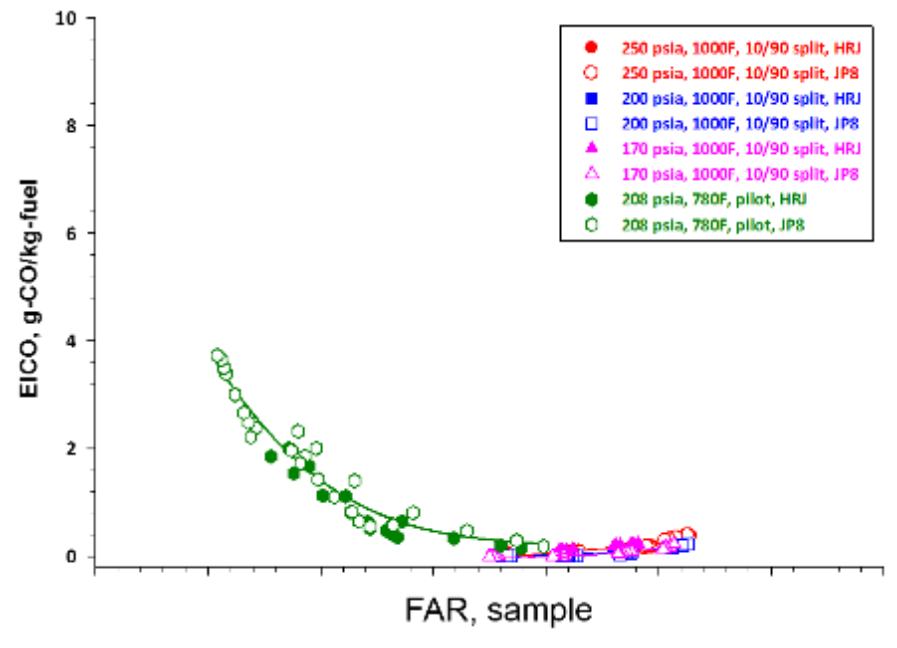

Figure 5. CO emissions as a function of FAR, T3, P3, and fuel split for JP-8 and HRJ.
EINOX for the 10/90 fuel split conditions is plotted on a semi-log graph and shows an exponential relationship to FAR (which scales with combustion temperature), and increases with combustor inlet pressure. EICO is very low for all 10/90 fuel split cases.

\section{B. Chemiluminescence from $\mathrm{CH}^{*}$ and $\mathrm{C}_{2}$ *}

We make use of Figs. 6 - 9 to describe the chemiluminescence results discussed later in this section. We begin with a detailed description of how the data were obtained and a little on the image processing.

Chemiluminescence images capture the light emitted throughout the volume of the optically-accessible region and do not isolate individual planes as is the case with PLIF and PIV. Each image is a line-of-sight integration through the flow field. We computed the mean signal from a sequence of images on a pixel-per-pixel basis for all test cases, with

the results shown as contour plots in Fig. 6. (CH*, ICCD camera) and Fig. 7. ( $\mathrm{CH}^{*}$ and $\mathrm{C}_{2} *$, high speed CMOS camera). For the high speed camera results, the images are of the root-mean-square (RMS), rather than the arithmetic mean. This is because we did not use a filter to isolate $\mathrm{C}_{2} * \mathrm{or}^{*}$; therefore, we did not block the spectral noise from water, noise from blackbody radiation, or random motions noise, which are unchanging for a given inlet condition. These noise sources distort the interpretation of the arithmetic mean. By eliminating this constant noise through subtracting the arithmetic mean from each image, we eliminate the extraneous signal, leaving just the relevant signal. The RMS is also useful because it shows where the largest changes in flame luminosity occur. The RMS images for points 2 and 4 are cropped to emphasize the structure from the TAPS main circuit region.

We did not use an isolation filter for the high speed camera because in using our stock $\mathrm{CH}$ or $\mathrm{C}_{2}$ filters in earlier work, we had very poor image quality at the frame rates of interest, given that our filters have at best $50 \%$ transmittance. Recent advances in spectral line filter technology can produce filters with much better transmission characteristics than we had available when we acquired our data.

One difference between the images acquired using the ICCD camera and those acquired with the high speed CMOS camera is the total acquisition time represented by the data. The $\mathrm{CH}^{*}$ images using the ICCD were collected in two ways. The 600-gate, 100-ns, on-chip averages shown in the top row of Fig. 6 each represent an acquisition time of one minute, but the total of all the exposure periods in each image set is $60-\mu \mathrm{s}$. Those averages calculated from singleshot images (Fig. 6, rows 2 - 4) had individual exposure times of $100 \mu \mathrm{s}$, and were collected at a rate of approximately one per second; thus, the single-shot averages each represent a total acquisition time of 100 seconds. The two acquisition settings were chosen to match the exposures of PLIF and PLS on the one hand, and the high speed movies on the other. The hexagon pattern seen in the top row images arises from the fiber coupling of the image intensifier to the CCD array and is only apparent for low light signals; and indicates that for the 100-ns exposures, the luminescence signal is small. However, the $\mathrm{CH}^{*}$ luminescence pattern revealed using the averages of the single-shot mode appear identical to the on-chip averages. The reason we present the on-chip averages instead of the single-shot averages in the top row of Fig. 6 is that the 100- $\mu$ s exposure single-shot images were over-saturated for both the JP- 8 and the blend, resulting in loss of detail due to extensive pixel blooming.

For the high speed camera, we acquired images until the 8GB camera buffer filled, which took about one second. A total of 9701 images was acquired during that time. The maximum exposure time at that frame rate was $100-\mu \mathrm{s}$.

The pilot flow appears to have the greatest effect on flame structure, regardless of fuel type. For the 100\% pilot case (top row, Figs. $6 \&$ 7), we see the upper portion of the conical spray, with the greatest signal appearing downstream. It also seems the highest signal appears farther downstream for the HRJ. For the $20 \%$ pilot condition ( $3^{\text {rd }}$ row), the highest signal appears lower in the image, closer to where the pilot is located. We also see from the luminous structure indicated by the RMS images, the $20 \%$ pilot case is similar to the $100 \%$ pilot case. When comparing the $20 \%$ case to the $10 \%$ pilot case at the same inlet temperature (row 3 compared to row 2), the distinction is clear; for the

American Institute of Aeronautics and Astronautics 
$10 \%$ pilot case, most of the signal emanates at a radial (vertical) position closer to the main injector position compared to the $20 \%$ pilot flow case. At the highest inlet temperature, the "structure" for $10 \%$ pilot flow is unchanged (compare rows 2 and 4). The high speed camera RMS images reveal that the greatest variations at point 2 occur close to the dome for the HRJ; this may be indicative of the expected shorter ignition delay time of HRJ compared to JP- 8 . At the higher inlet temperature, point 4, although there is still more change near the dome for the HRJ compared to the JP8/air flame, the overall structures revealed downstream for the two fuels is more similar than at point 2; this may indicate the JP-8 is approaching HRJ in terms of vaporization.

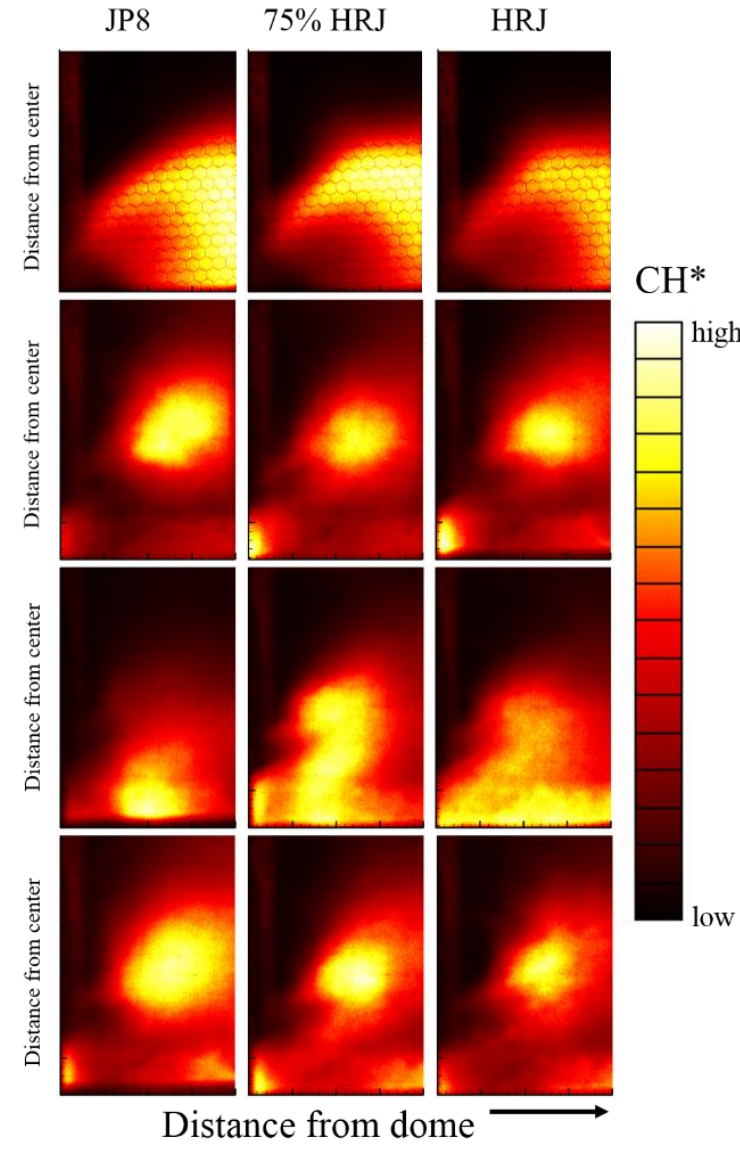

Figure 6. Average $\mathrm{CH}^{*}$ chemiluminescence signal for four inlet conditions (rows) and three fuel blends: 100\% JP-8 (left column), 25\% JP-8/75\% Alternate (center) and $100 \%$ Alternate (right). Top row: Onchip averages of 600, 100-ns gate exposures for point 1. Rows 2, 3, and 4: Averages of fifty, 100- $\mu$ s gate exposures for points 2,3 , and 4 , respectively.

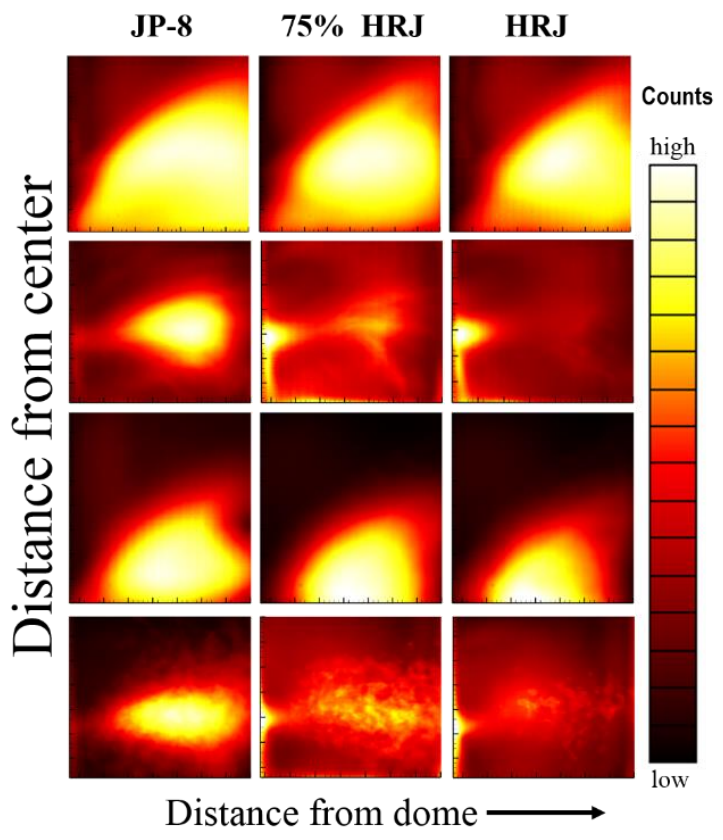

Figure 7. Root-Mean-Square of the luminous signal derived from individual high speed camera frames. Rows top to bottom are points 1 to point 4, respectively. Each image is self-scaled. For points 2 and 4, the images are cropped at the bottom (nearest the pilot region) to emphasize the key signal that emanates from the main circuit.

One other feature to note, as indicated by the pilot-only case, is the difference in cone shape when only JP-8 is used versus either level of HRJ fuel. In addition to the $\mathrm{CH}^{*}$ shown in Fig. 6, we see this same effect in laser scatter from the liquid fuel, and OH PLIF, discussed in later sections: for JP-8, we can see (to the extent of the field-of-view) a full conical shape, but for the HRJ fuel cases, the outermost flare appears truncated. The reason for the truncation is that when operating pilot only, the main fuel circuit is purged with nitrogen, and the nitrogen-rich region immediately downstream prevents/slows the fuel-air mixing in that area, minimizing the reactivity there. Although the nitrogen purge is also active for JP-8, its effect is not as obvious (perhaps because JP-8 is more dense); the effect of purge can be seen in the fuel PLIF end views of Fig. 15, and is discussed later. 

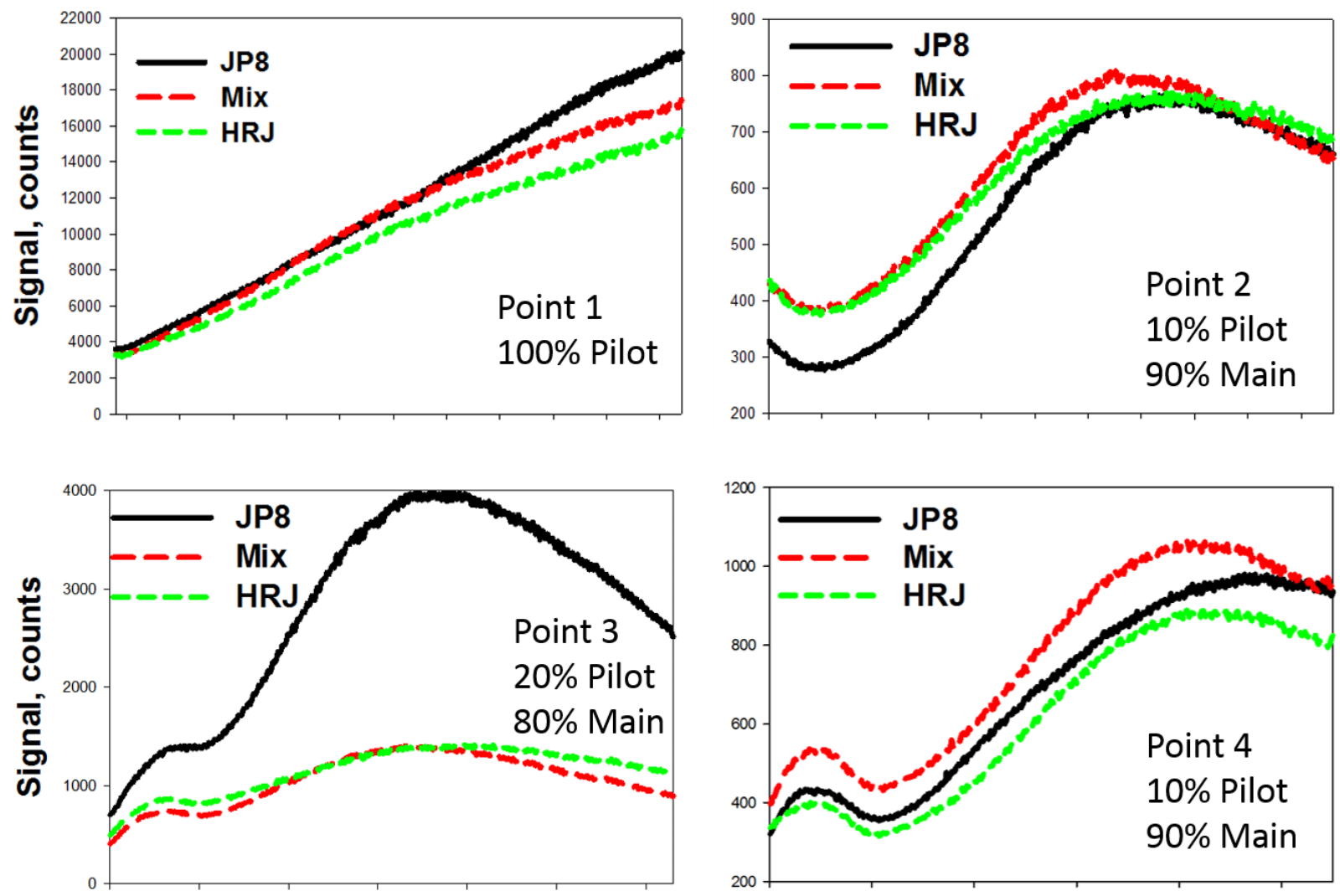

Distance from dome

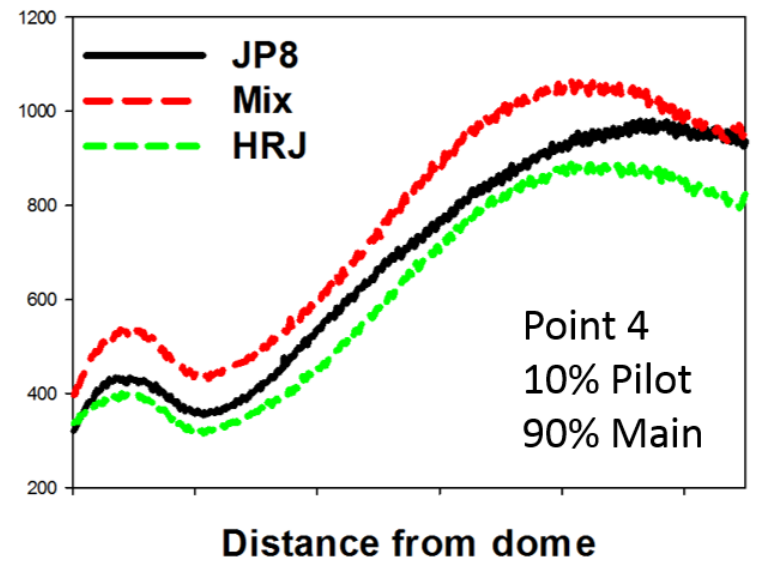

Figure 8. $\mathrm{CH}^{*}$ average signal per column for the images of Fig. 6 as a function of distance from dome, for each test point (graphs) and each fuel mix.

We compare the relative flame luminosity using the images in Figs. 6 - 7, and the graphs in Fig. 8, which plot the average luminous intensity for each column of the images as a function of distance from the dome. For Fig. 6, the fuel split cases (rows 2,3,4) can be compared directly since they had the same exposure, and the images for the pilot only case (top row) can be compared to one another on a separate basis.

For the pilot-only case (top row, Fig. 6), the intensity is highest for JP-8 and lowest for HRJ. This result is consistent with the higher aromatic content of JP-8, leading to greater emission of particulates. Although the overall FAR is fuel-lean, the local FAR is rich, which typically leads to more soot production, and more blackbody radiation.

It is relatively simple to discern the difference in luminous intensity by eye for the $100 \%$ pilot case, but not as simple to tell for the fuel split cases. For those, the graphs in Fig. 8 are useful. There are four graphs, one for each test point, as labeled, and each graph plots the signal for the neat fuels and the fuel blend. The upper left graph shows the pilot only results for point 1 , and confirms what we saw from the images directly. For the case of point 3 (lower left graph), which is the 20/80 fuel split case, we again find the JP-8 luminosity to be higher, than that of HRJ. However, in this case, there is little difference between the fuel blend and the pure HRJ, which both have considerably lower luminous intensity than the JP-8. The two graphs on the right of Fig. 8 plot the 10/90 fuel split results, and show very little difference between the fuels for luminosity. In summary, we again saw a difference in intensity based on the percentage of fuel to the pilot, with greater overall luminosity for the cases with at least 20\% pilot, and for the 10/90 split cases, no real differences. The highest luminosity was for point 1 , then point 3 (20/80 split), followed by point 4 , the 10/90 split at higher inlet temperature, then by point 3 .

We processed the high speed images in a manner like time-resolved PIV processing, and show the results for the pilot-only (point 1) condition in Fig. 9. As they are based on line-of-sight images, the results represent the bulk fluid motion. The contours, plotted on the same scale, reflect the rate of change within the flame zone. The vectors can be 
interpreted as showing the average direction of motion within the flame zone. All vectors are the same length, to better highlight fluid travel direction.

From the vectors we see a recirculation zone forms (lower part of the image). For the HRJ-fueled system, this zone is stronger, with the vectors directed upstream, whereas for the JP-8, the vectors show the fluid moves radially away from the centerline, and is indicated by the location of greatest change, as reflected by the highest signal region of the contour.
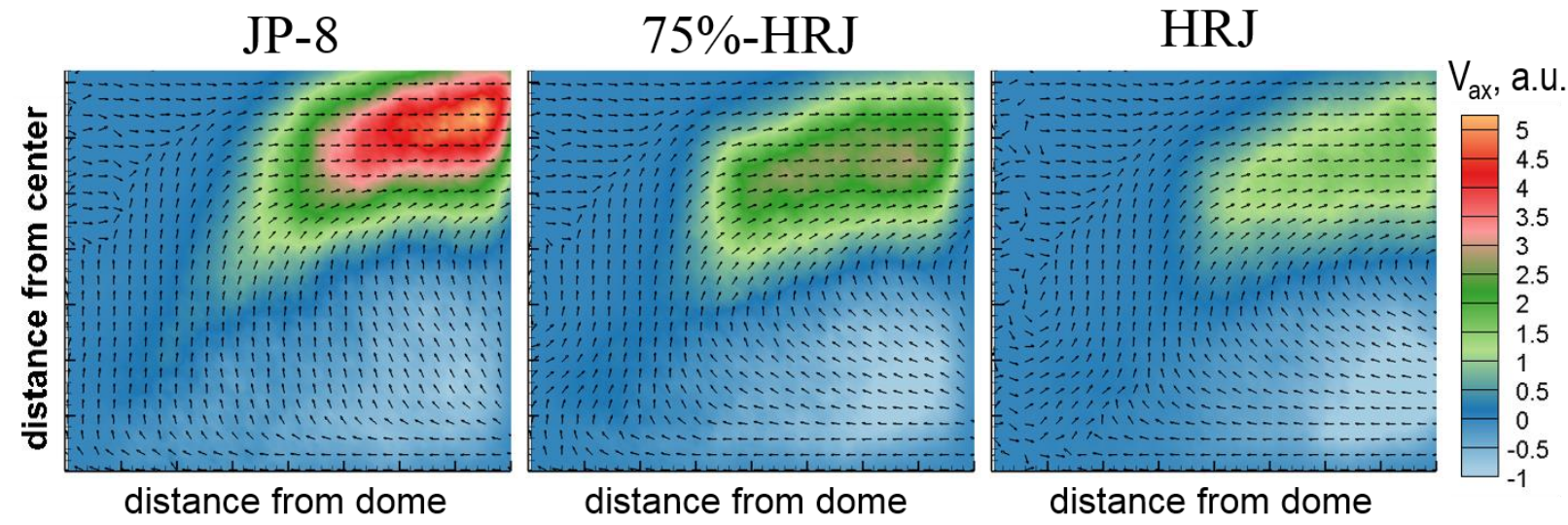

Figure 9. High-speed image pair sets processed like Particle Imaging Velocimetry for test point 1. Vectors indicate direction of flow. Colors indicate rate of change in the flow.

\section{Fuel Spray}

As mentioned in the introduction, this was our first use of laser-based instrumentation with an alternative fuel. Some expectations we have are that for fuel PLIF, there will be a lower signal for HRJ than for JP-8. This is because the laser wavelength ( 282-nm, used for OH PLIF, and for PLS) excites the aromatics in the fuel, the naphthalenes and methyl-benzenes ${ }^{20,21}$ primarily, of which very few exist in the HRJ (on the order of 50 times less than in JP- $8^{12}$. Saturated hydrocarbons are essentially invisible to the laser wavelength we use (cyclohexane, iso-octane, dioxane, and iso-octane are typical solvents for UV analysis of aromatic compound ${ }^{22,23}$ ). We generally find the combusting system fluid to be optically-thick, especially for JP-8 and Jet-A, in part because there are many absorbing molecules, and also because some fluorescence is lost to collisions as the light travels through the system of molecules. For the HRJ fuel, we also expect the laser scatter signal may be higher than for JP-8 for a similar reason. Since there are fewer molecules that absorb the laser, then likely many more are available to scatter the laser light.

For OH PLIF, we tune the laser wavelength to excite $\mathrm{OH}$ molecules and tune the laser to a wavelength that does not excite to collect the background fluorescence. The aromatic absorbers are a source of background noise because whether we tune on- or off-line for $\mathrm{OH}$ excitation, the aromatics are excited. To obtain the $\mathrm{OH}$ signal we subtract from the on-line OH, the off-line (fuel PLIF) signal. Because the HRJ has fewer aromatics, the background signal is likely to be cleaner, and the system less optically-thick than for JP-8.

Figures 10 - 14 show the liquid fuel spray results obtained at the nominal vertical center plane, $y=0$. We typically acquired 100 single shots per inlet condition. Included among the results are a plot of the mean signals at the four inlet conditions for the different fuel mixes, examples of the single-shot images, and a representative graph that shows the PLS signal decay with distance from the dome. Figure 15 shows a comparison between JP-8 and HRJ by way of fuel PLIF, whose signal is a response from both liquid and vapor.

Considering first the pilot only condition, test point 1, Figs. 10-11 show some of the individual single-shot images acquired for the mixture and for the pure HRJ fuel. These show that the fuel can extend downstream the full extent of the field-of-view. The trajectory of the liquid spray appears to match up well with the outer boundary of the cone observed in the chemiluminescence images. This trajectory can also be observed in the top row of Fig. 12, which shows the average PLS signal over 100 single-shot images. The Fuel PLIF images for point 1 (Fig. 15, left column, top two rows), show a similar pattern for both JP-8 and HRJ. In Fig. 15, the images on the left are side views at Y=0 and show how the fuel is dispersed downstream while the two images in the next two columns on the right are end view slices derived from the composite block of images processed from the traverse across the combustor. The end views show signs that the fluid is optically thick because the signal is stronger on the side (right) closest to the camera. The slices are relatively close to the dome exit so that we can observe the structure a short distance away. In these end

American Institute of Aeronautics and Astronautics 
views, there is a gap in the fluorescence at the top that corresponds to the nitrogen purge passing through the main fuel circuit. The gap is larger for the HRJ fuel than for the JP-8, which may be related to the lower density of HRJ. In terms of overall extent downstream for the liquid phase HRJ fuel, although the instantaneous images (Fig. 11) show the liquid can extend as far downstream within the field of view as the JP-8/HRJ mix (Fig.11), on average (Fig. 12, top row) the bulk of HRJ liquid signal has dissipated just a short distance from the dome exit.

For the inlet cases that have a fuel split (rows 2, 3, and 4 of Fig. 12), we observe a liquid fuel signal from the main circuit only. Any fuel from the pilot circuit is likely evaporated by the time it reaches the dome exit considering fuel flow through the pilot is at most $20 \%$ of the main fuel flow, and at greater inlet air temperature than at point 1 . We also note from Fig. 12 the main circuit liquid evaporates downstream within the distance of the main passage annulus height, which is true no matter the fuel. For example, Fig. 13 shows a plot of the normalized total PLS signals for JP8 and HRJ at test point 4, as a function of distance from the dome. This plot is representative of all inlet conditions, in which we see an apparent faster decay of liquid JP-8 compared to HRJ. This may, however, also be due to the higher laser scatter signal (because less laser light is absorbed by aromatics) for HRJ. Regardless, results for both fuels show a relatively short distance before all fuel can be considered vaporized, as we saw in the images in Fig. 12.

Figure 12 also shows the main circuit fuel distribution is bifurcated about the center of the main circuit annulus. Some of the main circuit fuel wets the outer wall, with less indication of liquid within the annulus. Most of the liquid, however, stays near the inner surface of the annulus. The Fuel PLIF images for point 2 (bottom two rows of Fig. 15) show a distinct difference between JP-8 and HRJ fuel. First, most of the HRJ fuel (bottom row) seems to be consumed shortly after entering the combustion chamber (side view). The end views show more fuel signal along the wetted walls than in the center of the annulus. This is contrary to what is observed for JP-8, where the side view shows the fuel signal extends downstream, though not as far as for the pilot only case (top row). The end views show the fuel uniformly distributed within the annulus. The lack of fuel PLIF signal from the HRJ throughout the annulus for point 2 may also be related to the lack of aromatics in HRJ, such that when the fuel is in the gas phase (presumably in the center of the annulus) the PLIF signal is very weak; in the liquid phase, the PLIF signal is considerably stronger because the number density of absorbing molecules is greater than in the gas phase.

Figure 14 compares the total PLS signal per kilogram of fuel in the regions outlined by the boxes in Fig. 12. The boxes outline the location for which we saw liquid signal, on average. For each inlet condition, we determined the PLS signal increases with the percentage of HRJ, meeting the expectation that more laser energy is available for scatter because of less absorption by the fuel.

\section{D.Flame Zone}

Figure 16 shows the OH PLIF results for points 1 and 2, which we can compare with regard to fuel type. As with the fuel PLIF (Fig. 15, described above in section C), a side view and two end views are shown, although the OH slice on the right is at a position farther downstream than for fuel. The end view images show signs of optical thickness, more so for JP-8 than for HRJ.

For point 1 (Fig. 16, top two rows), the side view images indicate that the primary reaction occurs along the fuellean side of the fuel spray, farther away from the centerline. In the JP-8 case, we also see that $\mathrm{OH}$ forms in a region more centrally-located relative to the TAPS centerline, downstream of the pilot, in its central recirculation region (CRZ). For the HRJ fuel, however, we do not see much OH in the CRZ. We do not have enough information from OH PLIF alone to say whether the reactions have already occurred within the pilot fuel cup region and $\mathrm{OH}$ has already been consumed by the time the fuel exits the dome, or it has yet to form. Another difference for HRJ is that the "flattened" profile we saw with the PLS and $\mathrm{CH}^{*}$ images can be seen in the OH PLIF image. Considering the end views, the structure near the dome exit is similar for the two fuels, but farther downstream the OH in the CRZ is much more apparent for the JP-8 than for the HRJ. The CRZ OH location farther downstream for the HRJ fuel is consistent with observing the $\mathrm{CH}^{*}$ signal (Fig. 6) also downstream.

For point 2 , which is a $10 \%$ pilot condition, the primary region of $\mathrm{OH}$ formation is closer to the pilot region, and the location and structure are similar for both fuels.

Figures 17 and 18 show fuel and OH PLIF results using JP-8 for all four test points. For the fuel split cases, the fuel patterns are similar, with a nominally uniform distribution within the annular volume and more fuel observed within the center section of the 20/80 split (point 3) compared to the 10/90 split cases (points 2 and 4). For OH, nearly all the $\mathrm{OH}$ is observed within the CRZ region. Again, as we saw for the chemiluminescence images for $\mathrm{CH}^{*}$ and $\mathrm{C}^{*}$, the side view $\mathrm{OH}$ for point 3 has a different appearance than that of the 10/90 split cases; there is likely more interaction between the pilot and main flow regions for the 20/80 split.

American Institute of Aeronautics and Astronautics 


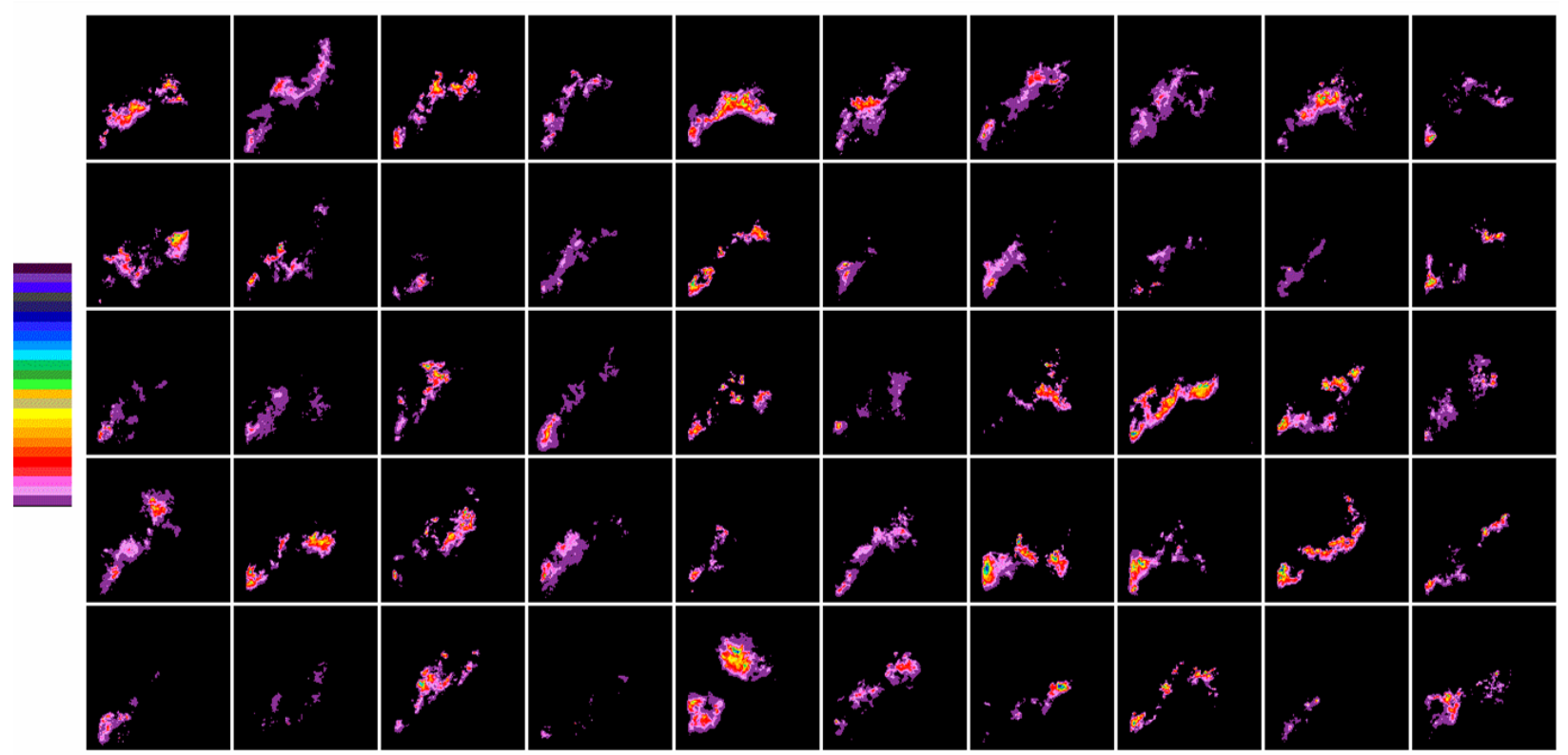

Figure 10. Fifty of the individual instantaneous (100-ns exposure) planar laser scatter (PLS) images obtained at test point 1 for the JP-8/HRJ fuel blend. Flow is left to right in each image.

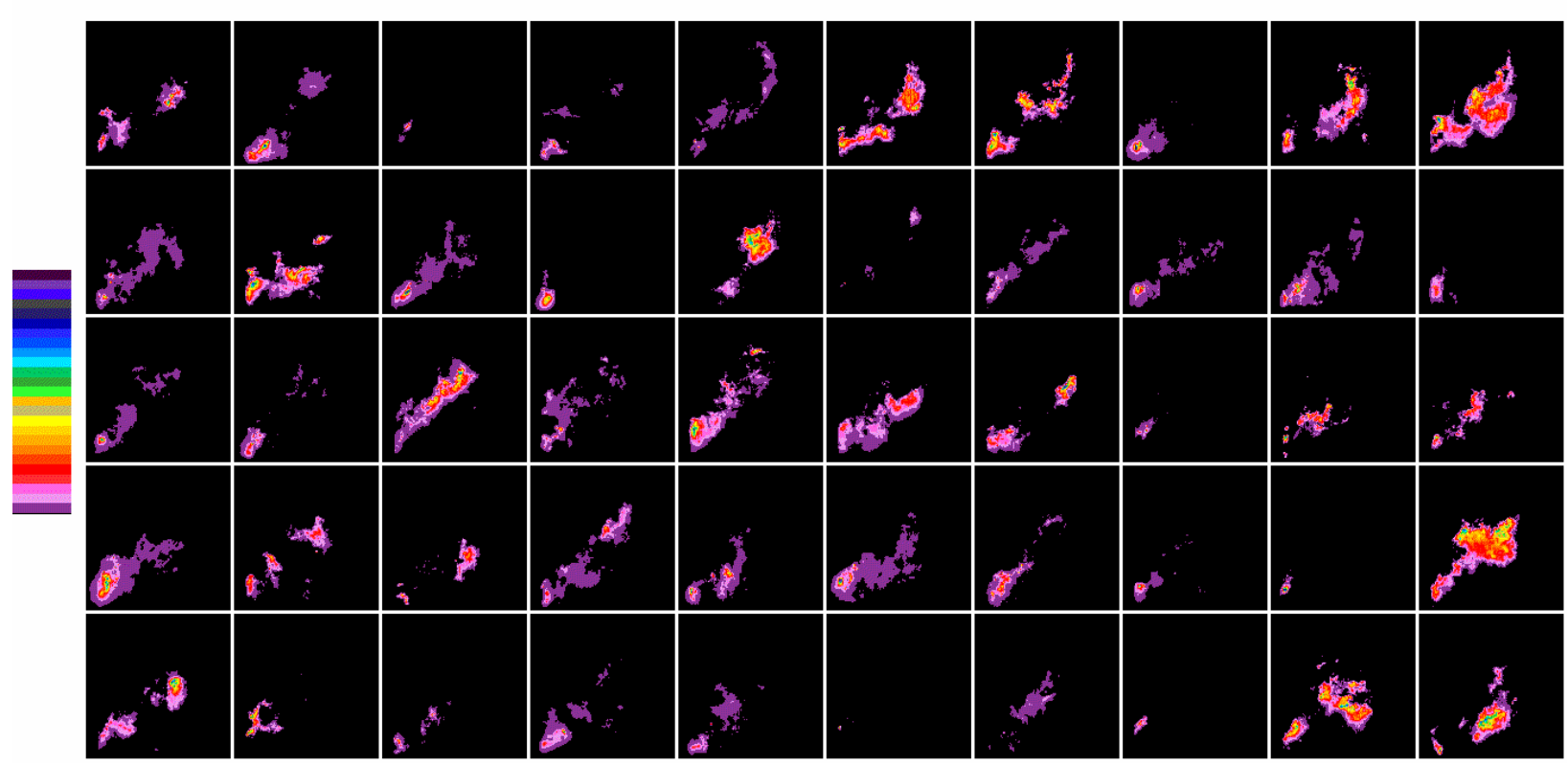

Figure 11. Fifty of the individual instantaneous (100-ns exposure) planar laser scatter (PLS) images obtained at test point 1 for the HRJ fuel. Flow is left to right in each image. 


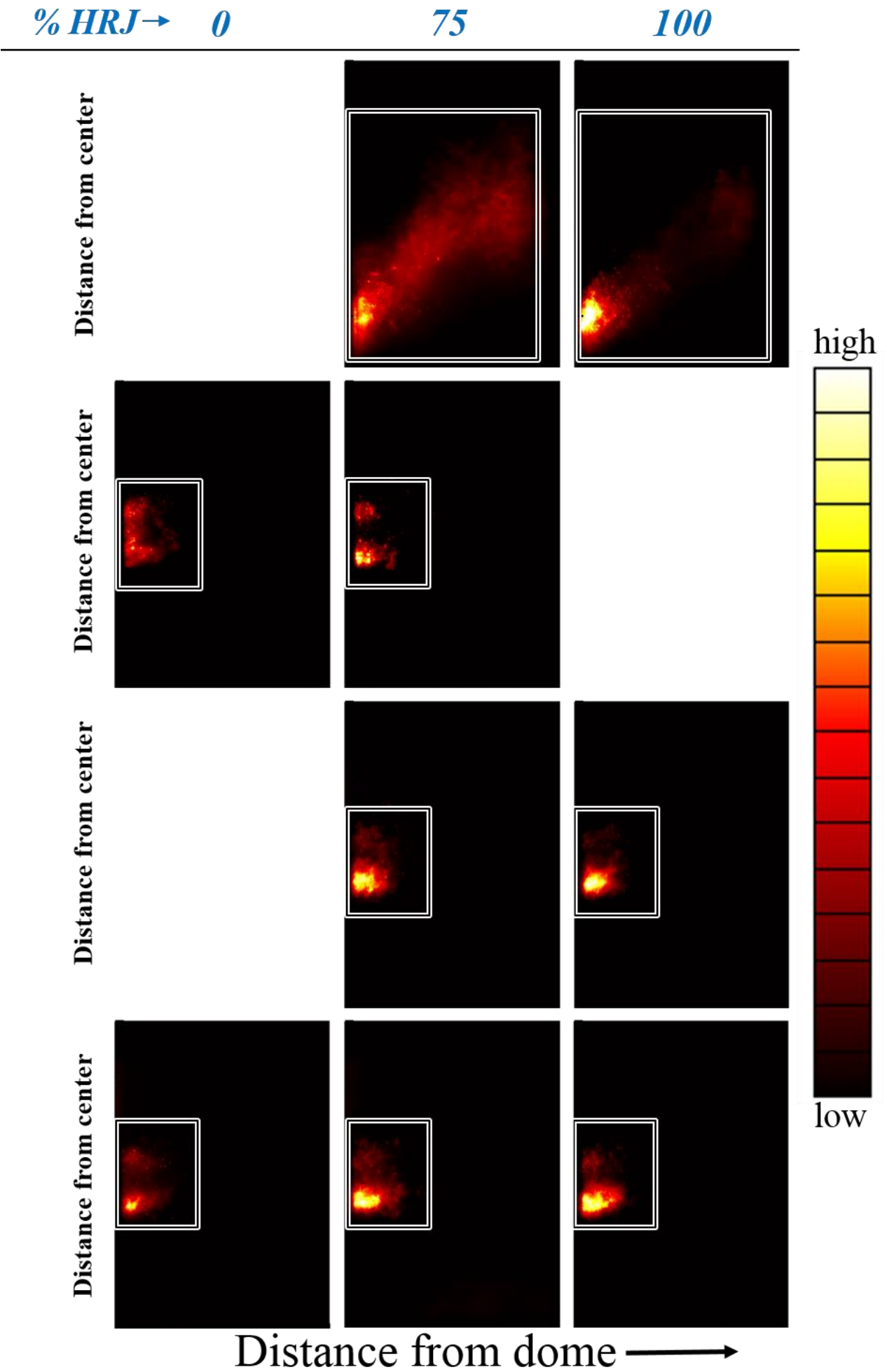

Figure 12. Mean PLS signal for selected fuel mixes at the four inlet conditions $1-4$ (rows 1-4, respectively). Flow left to right. The rectangular boxes outline the regions of interest used to produce the graph in Fig. 14. 


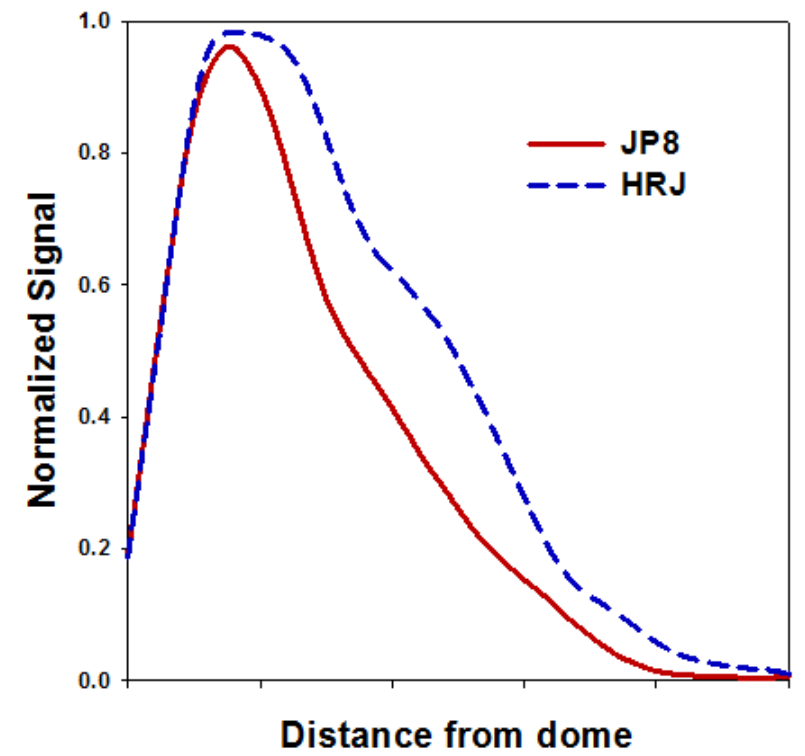

Figure 13. Comparing liquid fuel signal decay between JP-8 and HRJ fuels at test point 4. These normalized plots were derived by summing the signal of each column of pixels in the respective PLS mean images (bottom row, Fig. 12).

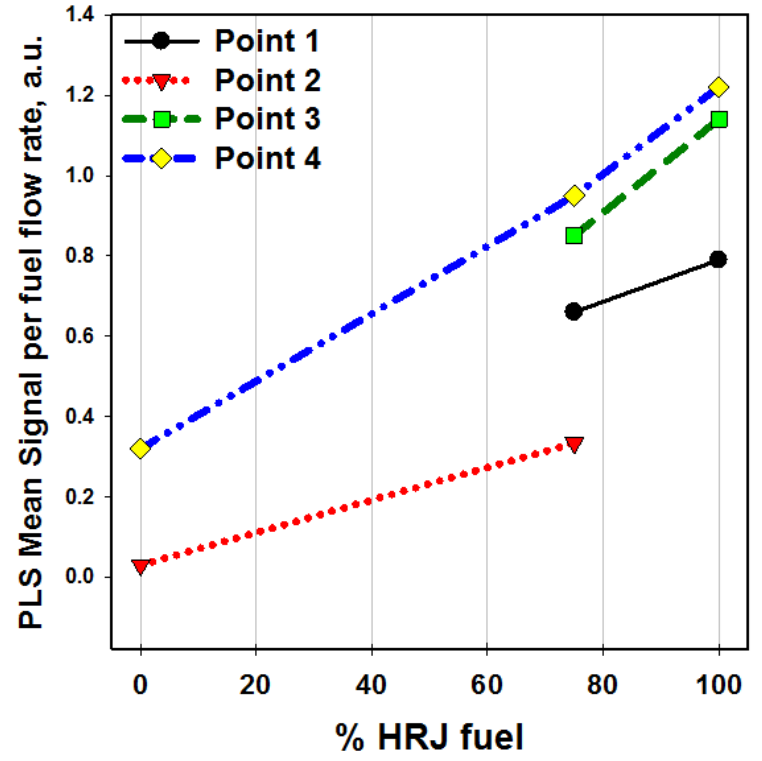

Figure 14. PLS mean signal, normalized by fuel flow rate, as a function of per cent HRJ fuel used at each inlet condition. 


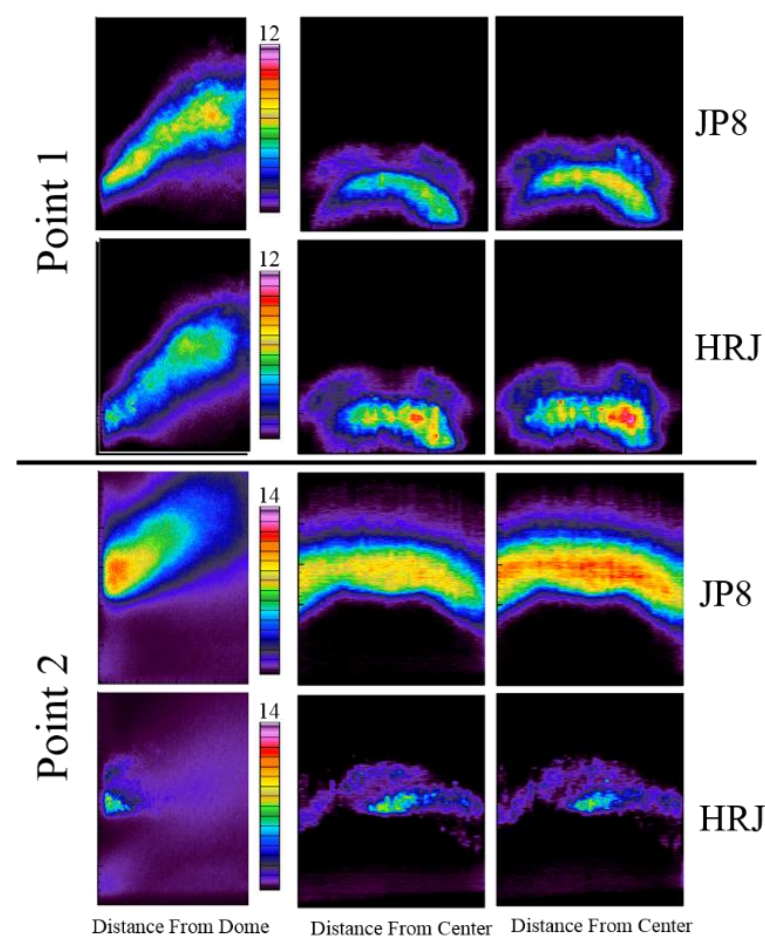

Figure 15. Comparison between JP-8 and HRJ fuel distribution as indicated by Fuel PLIF for point 1 (top two rows) and point 2 (bottom two rows. Left column: Side view along $Y=0$, with flow from left to right. Center and right columns: End views at two axial locations, with flow out of the page.

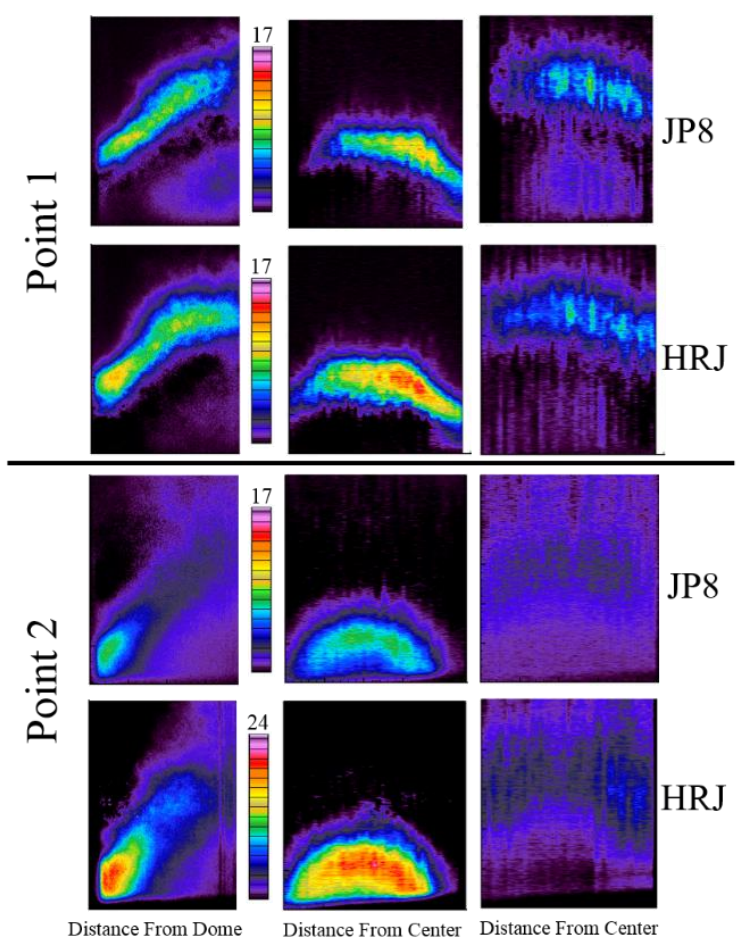

Figure 16. Comparison between JP-8 and HRJ fuel distribution as indicated by OH PLIF for point 1 (top two rows) and point 2 (bottom two rows. Left column: Side view along $Y=0$, with flow from left to right. Center and right columns: End views at two axial locations, with flow out of the page.

\section{Conclusion}

We have presented experimental analyses of a GE TAPS injector comparing results using JP-8 fuel with results using HRJ fuel. Consistent with other alternative fuel combustor and engine tests, we found little or no difference in gaseous emissions of NOx, CO, and unburned hydrocarbons.

Chemiluminescence and laser-based measurement methods were used to examine spray and flame characteristics for four different test conditions and two types of fuel plus a mixture of the two fuels. JP-8 fuel and HRJ fuel were used. From average chemiluminescence images we see that the luminous flame structure changes depending on the percentage of fuel flow to the pilot injector, independent of the fuel type. The pilot flow appears to have the greatest effect on flame structure. There is a difference in cone shape when only JP-8 is used versus either level of HRJ fuel.

For the inlet cases where the fuel is split between pilot and main we observed a liquid fuel signal from the main circuit only. This indicates that any fuel from the pilot circuit is likely evaporated by the time it reaches the dome exit. We also note that main circuit liquid evaporates within a downstream distance equal to annulus height, no matter the fuel. There is indication that the main circuit fuel distribution is bifurcated about the center of the main circuit annulus. Some of the main circuit fuel wets the outer wall, with less indication of liquid within the annulus. Most of the liquid, however, stays near the inner surface of the annulus.

The OH PLIF results indicate that the primary reaction occurs along the fuel-lean side of the fuel spray, farther away from the centerline. In the JP-8 case, we also see that OH forms in a region more centrally-located, but downstream of the pilot, in its central recirculation region (CRZ). For the HRJ fuel, however, we do not see much OH in the CRZ. Considering the end view slice OH PLIF images, the structure near the dome exit is similar for the two fuels, but farther downstream the $\mathrm{OH}$ in the CRZ is much more apparent for the JP-8 than for the HRJ. For the 10\%/90\% split

American Institute of Aeronautics and Astronautics 


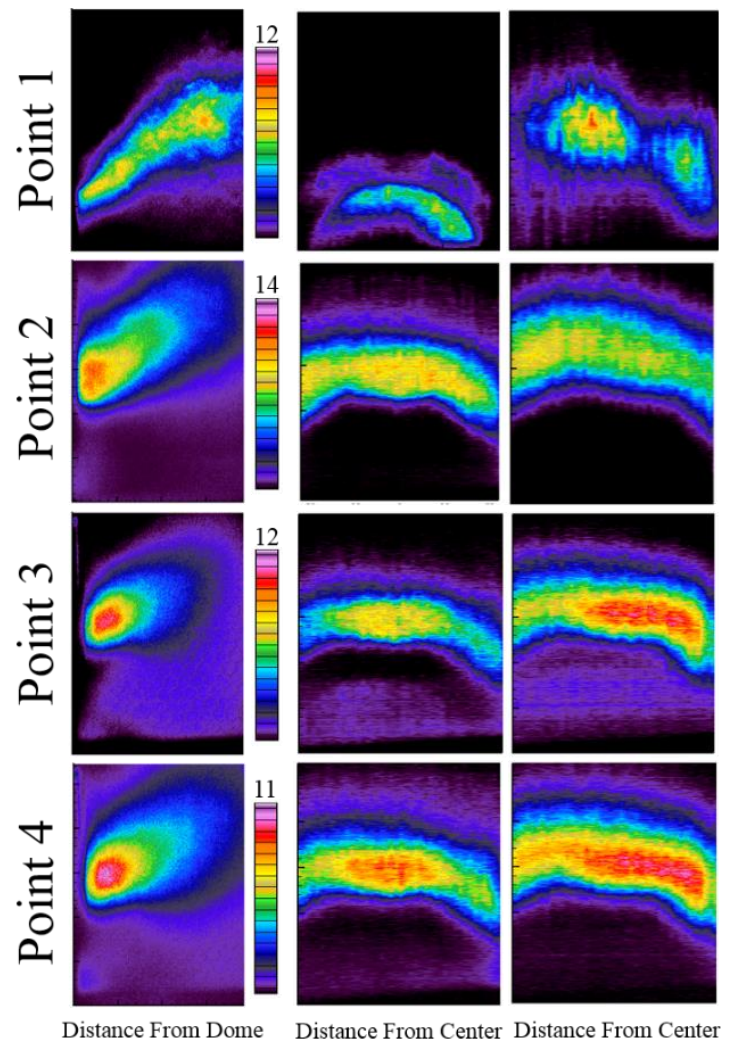

Figure 17. Fuel PLIF results using JP-8 fuel for points 1 - 4 (rows). Left column: Side view along $Y=$ 0, with flow from left to right Center and right columns: End views at two axial locations, with flow out of the page.

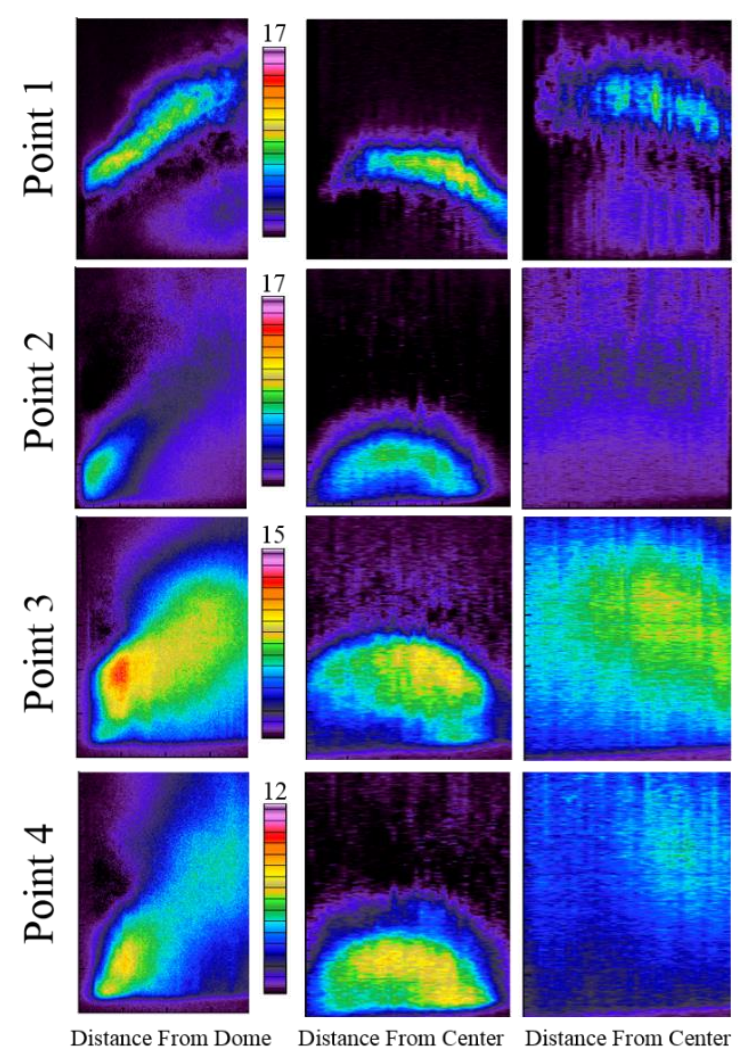

Figure 18. OH PLIF results using JP-8 fuel for points 1 - 4 (rows). Left column: Side view along $Y=0$, with flow from left to right Center and right columns: End views at two axial locations, with flow out of the page.

case, the primary region of $\mathrm{OH}$ formation is closer to the pilot region, and the location and structure is similar for both fuels.

The Fuel PLIF images for the 10\%/90\% pilot-to-main split show a distinct difference between JP-8 and HRJ fuel. First, most of the HRJ fuel seems to be consumed shortly after entering the combustion chamber. The end views show more fuel signal along the wetted walls than in the center of the annulus. This is contrary to what is observed for JP8 , where the side view shows the fuel signal extends downstream, though not as far as for the pilot only case. The end views show the fuel uniformly distributed within the annulus. This difference illustrates the difference based on the spectral characteristics of the fuels relative to aromatic content.

When using laser-based diagnostics with the alternative fuels, laser scatter from liquid fuel works well, but fuel PLIF of the vapor does not because of the limited number of absorbing aromatic molecules in the fuel. Since we were limited in HRJ fuel supply, we had very little data to draw from for the JP-8/HRJ mixture, but we expect that using a 50/50 blend will provide good results for both PLS and fuel PLIF.

\section{Acknowledgments}

This work was supported by the Supersonics Project of the NASA Fundamental Aeronautics Program and by the NASA Environmentally Responsible Aviation Program. We thank Changlie Wey for his technical assistance and for providing the gaseous emissions results and Randy Locke for his assistance in conducting the experiments, and wish to acknowledge our industry partners at GE Aviation. 


\section{References}

${ }^{1}$ Lee, D.S., Pitari, G., Grewe, V., Grierens, K., Penner, J.E., Petzold, A., Prather, M.J., Schumann, U., Bais, A., Berntsen, T., Iachetti, D., Lim, L.L., and Sausen, R., Atmospheric Environment, Vol. 44, 2010, pp. 4678-4734.

${ }^{2}$ Bulzan, D., "Supersonics Project High Altitude Emissions Overview," 2012 Fundamental Aeronautics Program Technical Conference, 2012.

${ }^{3}$ Lee, C.-M., Chang, C., Kramer, S., and Herbon, J.T., "NASA Project Develops Next Generation Low-Emissions Combustor Technologies," Paper AIAA-2013-0540, 2013.

${ }^{4}$ Mongia, H.C., "TAPS - A $4^{\text {th }}$ Generation Propulsion Combustor Technology for Low Emissions," Paper AIAA 2003-2657, 2003.

${ }^{5}$ Foust, M.J., Thomsen, D., Stickles, R. Cooper, C. and Dodds, W., "Development of the GE Aviation Low Emissions TAPS Combustor for Next Generation Aircraft Engines,” Paper AIAA 2012-0936, 2012.

${ }^{6}$ Stickles, R. and Barrett, J., "TAPS II Combustor Final Report-Technology Assessment Open Report," FAA Continuous Lower Energy, Emissions and Noise (CLEEN) Program, Report number DOT/FAA/AEE/2014-03, 2014.

${ }^{7}$ Anderson, B. E.; Beyersdorf, A. J.; Hudgins, C. H.; Plant, J. V.; Thornhill, K. L., et al., "Alternative Aviation Fuel Experiment (AAFEX),”NASA/TM-2011-217059, 2011.

${ }^{8}$ Bulzan, D. et al, "Gaseous and Particulate Emissions Results of the NASA Alternative Aviation Fuel Experiment (AAFEX)," GT2010-23524, 2010.

${ }^{9}$ Colket, M. et al, "An Overview of the National Jet Fuels Combustion Program,” Paper AIAA 2016-0177, 2016.

${ }^{10}$ Allen, C., Valco, D. Toulson, E., Edwards, T. and Lee, T., "Ignition Behavior and Surrogate Modeling of JP-8 and of Camelina and Tallow Hydrotreated Renewable Jet Fuels at Low Temperatures," Combustion and Flame, Vol. 160, 2013, pp. 232239.

${ }^{11}$ Bruno, T.J. and Baibourine, E., "Comparison of Biomass-Derived Turbine Fuels with the Composition-Explicit Distillation Curve Method," Energy \& Fuels, Vol. 25, 2011, pp. 1847-1858.

${ }^{12}$ Corporan, E. et al, "Chemical, Thermal Stability, Seal Swell, and Emissions Studies of Alternative Jet Fuels," Energy \& Fuels, Vol. 25, 2011, pp. 955-966.

${ }^{13}$ Liu, Y.C., Savas, A.J., and Avedisian, C.T., "The Spherically Symmetric Droplet Burning Characteristics of Jet-A and Biofuels Derived from Camelina and Tallow," Fuel, Vol. 108, 2013, pp. 824-832.

${ }^{14}$ Smith, B.L., and Bruno, T.J., "Composition-Explicit Distillation Curves of Aviation Fuel JP-8 and a Coal-Based Jet Fuel," Energy \& Fuels, Vol. 21, 2007, pp. 2853-2862.

${ }^{15}$ Winchester, N., McConnachie, D., Wollersheim, C., and Waitz, I.A., "Economic and Emissions Impacts of Renewable Fuel Goals for Aviation in the US," Transportation Research Part A, Vol. 58, 2013, pp. 116-128.

${ }^{16}$ Wey, C., and Bulzan, D., "Effects of Bio-Derived Fuels on Emissions and Performance Using a 9-Point Lean Direct Injection Low Emissions Concept," GT2013-94888, 2013.

${ }^{17}$ Hicks, Y.R. and Tacina, K.T., "Comparing a Fischer-Tropsch Alternate Fuel to JP-8 and Their 50-50 Blend: Flow and Flame Visualization Results," NASA TM-2013-217884, 2013.

${ }^{18}$ Tacina, K.M., Chang, C.T., Lee, C.-M., He, Z., and Herbon, J., "Effects of Burning Alternative Fuel in a 5-cup Comubstor Sector," Ninth U.S. National Combustion Meeting, Paper No. 114IC-0317, 2015.

${ }^{19}$ Timko, M.T. et al, "Particulate Emissions of Gas Turbine Engine Combustion of a Fischer-Tropsch Synthetic Fuel," Energy \& Fuels, Vol. 24, 2010, pp. 5883-5896.

${ }^{20}$ Baranger, P., Orain, M., and Grisch, F., "Fluorescence Spectroscopy of Kerosene Vapour: Application to Gas Turbines," Paper AIAA 2005-828, 2005.

${ }^{21}$ Hicks, Y.R., Locke, R.J., Anderson, R.C., Zaller, M., and Schock, H.J., "Imaging Fluorescent Combustion Species in Gas Turbine Flame Tubes: On Complexities in Real Systems," Paper AIAA 97-2837, 1997.

${ }^{22}$ Friedel, R.A., and Orchin, M., Ultraviolet Spectra of Aromatic Compounds, Wiley \& Sons, New York, 1951, pp. 12-14.

${ }^{23}$ Berlman, I.B., Handbook of Fluorescence Spectra of Aromatic Molecules, $2^{\text {nd }}$ ed., Academic Press, New York, 1971, Chaps. 3-4, pp.114-115, 330.

American Institute of Aeronautics and Astronautics 